Indian J. Anim. HIth. (2019), 58(2) : 233-235

DOI: https://doi.org/10.36062/ijah.58.2.2019.233-235

Short Communication

\title{
MANAGEMENT OF SARCOPTIC MANGE IN RABBITS
}

\author{
K. P. SINGH', R.V. SINGH ${ }^{1}$, P. SINGH ${ }^{2}$ \\ N. ARORA ${ }^{3}$ AND S. SINGH ${ }^{4}$ \\ Government Veterinary Hospital, Deoranian, Bareilly \\ Department of Animal Husbandry \\ Uttar Pradesh-243 203, India
}

\begin{abstract}
A total 6 rabbits, 1-2 years old of both sexes were presented to Government Veterinary Hospital, Deoranian, Bareilly, with the history of hair fall, pruritis and skin lesions for the past 1-2 months. All the rabbits were previously treated but no response was observed. Clinical examination of the rabbits revealed normal physiological parameters and mucous membrane. The skin lesions were predominantly found on ears, fore limbs and hind limbs. The microscopic examination of the skin scraping from all the affected animals revealed presence of Sarcoptes species. All the affected rabbits were treated with injection ivermectin @ $0.2 \mathrm{mg} / \mathrm{kg}$ body weight, subcutaneously weekly once, syrup Liv 52 @ 4-5 drops, orally twice a day and lotion Kiskin (clobetasol propionate, 0.03\% + ofloxacin, $0.1 \%$ + miconazole nitrate, $2 \%$ + zinc sulphate, $3.0 \%$ ) applied topically over the lesion. All the rabbits respond the treatments within 15 days of therapy and recovered completely after 40 days of therapy.
\end{abstract}

Key words: Pruritis, Rabbits, Sarcoptes, Treatment

Rabbits are affected with wide variety of parasitic infestation, among which the incidence of mange is high (Rajeswari et al., 2001). Mange infestation is highly contagious and pruritic in nature and having zoonotic importance. Kumar et al. (2002) observed that mange is most obstinate, persistent and contagious diseases with zoonotic importance. Sarcoptic mange in rabbits first appears on the head and ear and then becomes generalized being associated with intense pruritis with the loss of hair (Soulsby, 1982).

\footnotetext{
"Corresponding Author

${ }^{1}$ Department of Pharmacology, Bhavdiya Institute of Pharmaceutical Sciences and Research, Ayodhya, Uttar Pradesh

${ }^{2}$ Department of Livestock Product Technology, C.V.A.Sc., GBPUAT, Pantnagar, U.S.Nagar, Uttarakhand ${ }^{3}$ Department of Veterinary Medicine, C.V.A.Sc., GBPUAT, Pantnagar, U.S.Nagar, Uttarakhand

${ }^{4}$ Manager, Veterinary Services, Brooke Hosptal for Animals, India
} 
Indian Journal of Animal Health, December, 2019

Management of Sarcoptic mange in rabbits

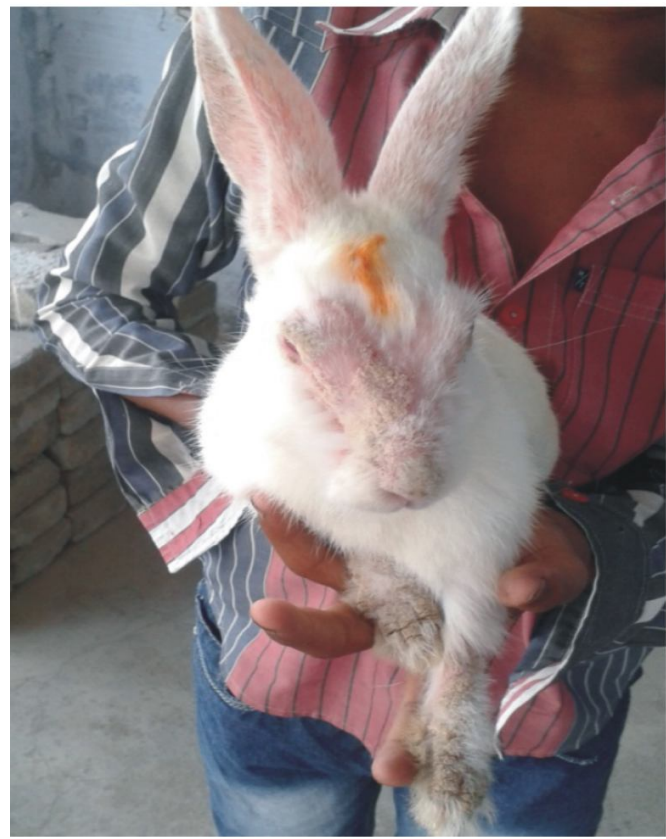

Fig. 1. Lesion present on the limbs, nostrils, face, eyes and ears.

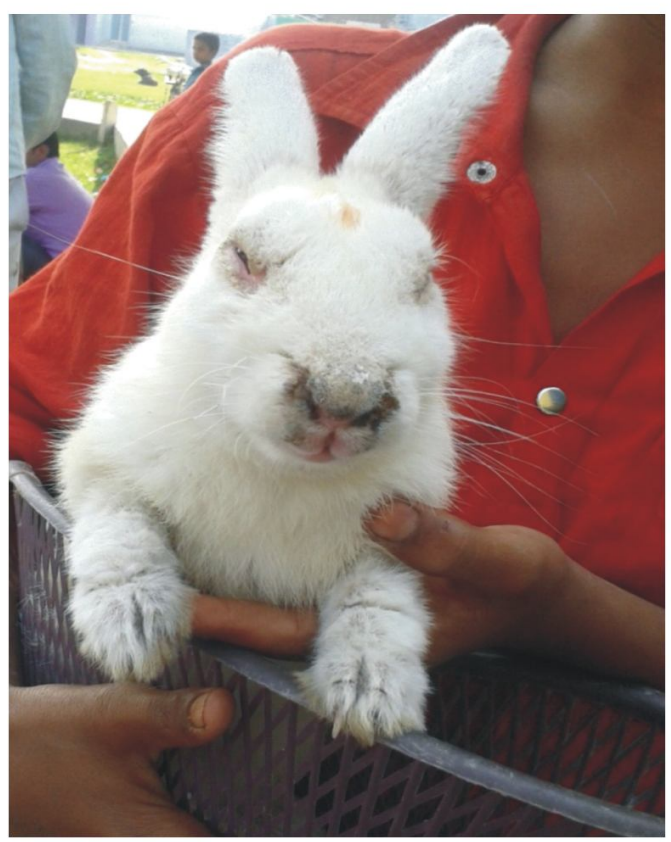

Fig. 3. After 15 days of treatment

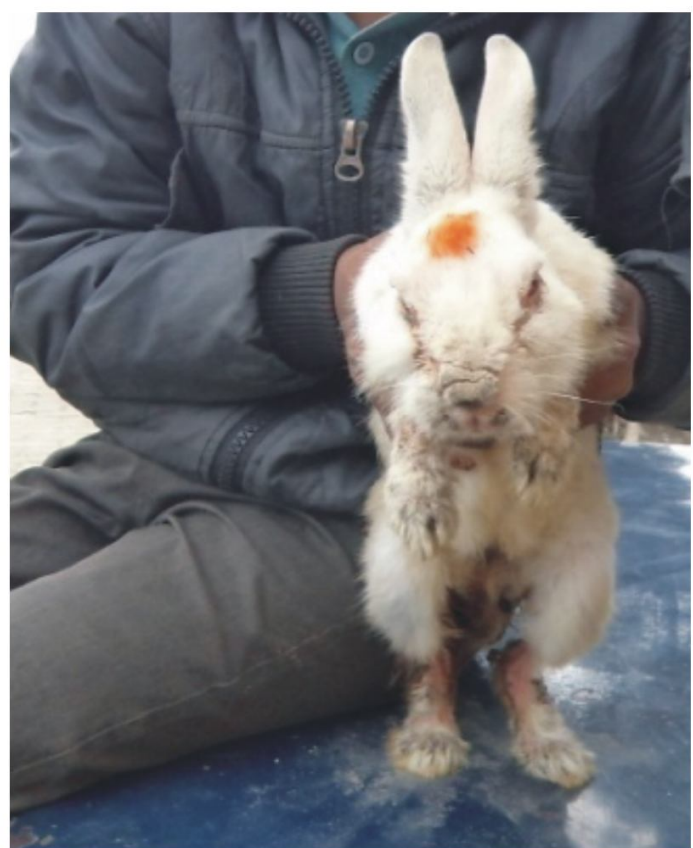

Fig. 2. Rabbits looked ugly in appearance

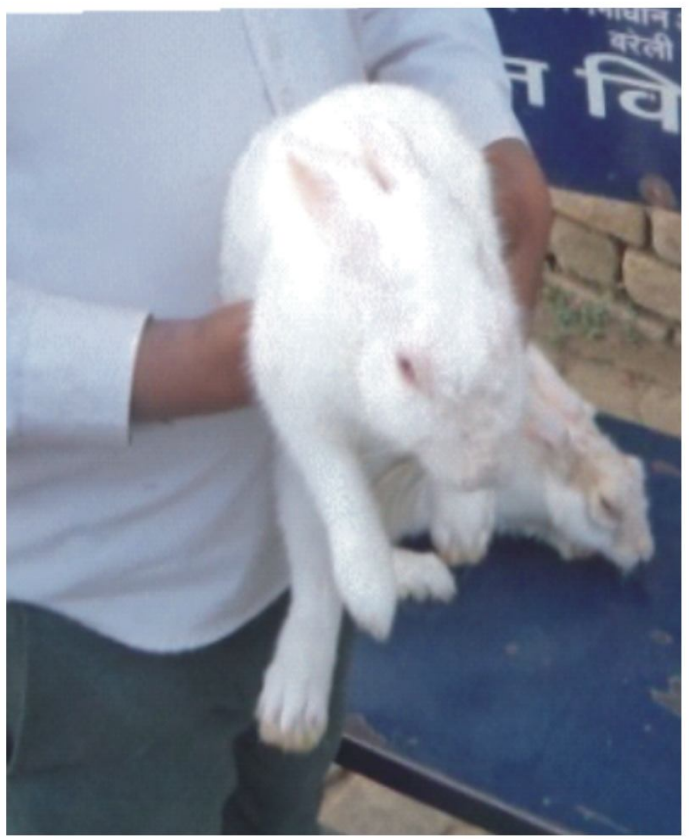

Fig. 4. After 30 days of treatment 
A total 6 rabbits, 1-2 years old of both sexes were presented to Government Veterinary Hospital, Deoranian, Bareilly, with the history of hair fall, pruritis and skin lesions for the past 1-2 months. All the rabbits were previously treated but no response was observed.

Clinical examination of the rabbits revealed normal physiological parameters and mucous membrane. Skin was wrinkled and dry crusts were noted on the face, upper part of the neck, around the eyes and on nostrils. Ear was severely affected and appeared as cotton made artificial ear due to heavy crust formation and dermatitis. The lesions were also observed on both fore limbs and toes of the fore and hind limbs. The lesion was pruritic in nature and on itching and scratching there was shedding of fur and it was also severely tagged (Fig. 1). The rabbits looked ugly in appearance and were dull, depressed and anorectic showing weakness and weight loss.

The microscopic examination of the skin scraping from all the affected animals revealed presence of Sarcoptes scabiei.

All the affected rabbits were treated with injection ivermectin@ $0.2 \mathrm{mg} / \mathrm{kg}$ body weight, subcutaneously weekly once, on day 0 , day $7^{\text {th }}$, day $14^{\text {th }}$ and day $21^{\text {st }}$, syrup Liv 52 @ 4-5 drops, orally twice a day for 30 days and lotion Kiskin (clobetasol propionate, $0.03 \%+$ ofloxacin, 0.1 $\%+$ miconazole nitrate, $2 \%+$ zinc sulphate, $3.0 \%$ ) applied topically over the lesion.

After each injection of ivermectin, deep skin scrapping examination has been performed to detect the presence of mange infestation. Weekly skin scraping examination indicated the reduction of concentration and severity of the infection of mange. All the rabbits respond the treatments within 15 days of therapy (Fig. 3). All the rabbits completely recovered with disappearing of itching and crust formation. Gradually crust started to disappear and after 28 days crust completely disappeared and patches of alopecia only left behind. Hair begins to grow on the patches of hair loss after 33-35 days (Fig. 4). All the rabbits showed complete recovery after 40 days of therapy.

Sarcoptes scabiei is highly contagious and burrow deep in epidermis of skin. This mite can very easily transmit to other surrounding animals through close contact. Treatment was initiated with injection ivermectin $@ 0.2 \mathrm{mg} / \mathrm{kg}$ body weight, subcutaneously weekly once, on day 0 , day $7^{\text {th }}$, day $14^{\text {th }}$ and day $21^{\text {st }}$ for four doses. Ivermectin selectively bind to glutamate gated and gammaaminobutyric acid (GABA) gated chloride channel in the mite nervous system resulting in hyperpolarization of cell, paralysis and death of mites. The present observations were similar to findings of Quesenbery (2000), Kumar et al. (2002) and Kumar et al. (2013). However, Panigrahi and Gupta (2013) and Mitra et al. (2014) reported subcutaneous administration of 4 doses of ivermectin@ 400 microgram $/ \mathrm{kg}$ body weight at 7 days interval was effective in treating Sarcoptic mange infested rabbits. Bhardwaj et al. (2012) compared efficacy of ivermectin and doramectin in rabbit affected with sarcoptic and psoroptic mange and found that ivermectin was more effective than doramectin. The skin lesions including itching, scratching and shedding of furwere treated with topical application of clobetasol propionate, $0.03 \%$ + ofloxacin, $0.1 \%+$ miconazole nitrate, $2 \%+$ zinc sulphate, $3.0 \%$. Syp Liv 52 was given as a hepatoprotectant and to improve 
appetite and alertness of rabbits.

In the present study, it is concluded that injection of ivermectin, oral administration

\section{REFERENCES}

Bhardwaj RK, Mir IA, Ahmad O, Kumar A, Wahid A et al., 2012. An outbreak of mange in rabbits. Indian Vet J, 89: 78

Kumar B, Kumar N and Sinha RK, 2013. Management of mange infection in New Zealand white rabbit. Indian J Vet Med, 33(2): 146-147

Kumar P, Sahay MN, Sinha VK and Samantaray S, 2002. Comparative efficacy of some acaricides against mange in dog. Indian Vet J, 79: 828-830

Mitra J, Shikari RN, Das AK, Roy BB and Mitra M, 2014. Therapeutic management of sarcoptic mange in rabbit with ivermectin. Explor Anim Med Res, 4(1): 116-120 of Liv 52 and topical application of Kiskin lotion is highly (100\%) effective for therapeutic management of Sarcoptic mange in rabbits.

Panigrahi PN and Gupta AR, 2013. Therapeutic management of concurrent Sarcoptic and Psoropticicariosis in rabbits. Intas Polivet, 14 (2): 319-321

Quesenbery, K, 2000. Rabbits. In: Saunders Manual of Small Animal Practice. $2^{\text {nd }}$ edn., W.B. Saunders, Philadelphia

Rajeswari YB, Udupa V and Suryanarayana T, 2001. Efficacy of Scavon in mange of rabbits. Ind Vet J, 78: 331-332

Soulsby EJL, 1982. Helminths, Arthropodes and Protozoa of Domesticated Animals. $7^{\text {th }}$ edn., pp483-485 